\title{
The road to societal trust: implementation of Towards Sustainable Mining in Finland and Spain
}

\author{
Pamela Lesser ${ }^{1}$ (D) \\ Received: 19 June 2020 / Accepted: 29 March 2021 / Published online: 13 April 2021 \\ (C) The Author(s) 2021
}

\begin{abstract}
In government, industry and academia, there is a convergence of three trends: (1) the belief that responsible exploration and mining should increase across Europe, (2) industry should follow and 'Europeanise' international good practices and (3) a social licence to operate exists not only between a community and a company but also between society and industry. There are two examples in Europe where these trends are converging-Finland and Spain have both adopted the Canadian Toward Sustainable Mining (TSM) program, but the method of implementation is very different. As a result of Talvivaara, Finland took a network governance approach incorporating trust-building measures from the beginning by bringing diverse stakeholders together to create the Finnish Network for Sustainable Mining. Spain chose to integrate the TSM into their national standards, a more traditional and hierarchical approach but one that also relies on a trustworthy entity with clear longevity. Although implementation is in the early stages in both countries, and therefore this paper provides insights only on preliminary outcomes, results indicate that the network approach may not be better at achieving societal SLO suggesting that other factors such as narrative, dialoguing directly with society, implementing trust-building measures in a timely fashion and proven longevity may have more influence than early trust-building measures between network participants.
\end{abstract}

Keywords Network $\cdot$ Standard $\cdot$ Social licence to operate $\cdot$ Finland $\cdot$ Spain

\section{Introduction}

The secure supply of raw materials for the European Union (EU) is a long-standing issue of concern, and the EU has sought numerous ways to address it, starting with the Raw Materials Supply Group in the 1970s, continuing with the launch of the Raw Materials Initiative in 2008 prioritizing raw materials (EC COM(2008)699 final) and most recently the Action Plan for Critical Raw Materials (EC COM(2020)474) encouraging the domestic industry. As part of the Action Plan, the Commission launched the European Raw Materials Alliance (ERMA) envisioned to be a stakeholder network involving all relevant interests including industrial actors along the value chain, EU countries and regions, trade unions, civil society, research and technology organisations, investors and NGOs who share the goal of supporting the extraction of critical raw materials (EC

Pamela Lesser

pamela.lesser@ulapland.fi

1 University of Lapland, Pohjoisranta 4, 96100 Rovaniemi, Finland
COM(2020)474). The day before ERMA's launch, however, a letter was delivered to the Commission with the signatures of approximately 234 civil society organisations and academics expressing their deep concerns about the narrative of the Action Plan (Civil Society open letter, 2020). European policy and European society are at a critical juncture in charting the future course of exploration and exploitation activities, and the tension between those who believe mining is critical for the energy transition and those who champion postconsumerism and resource decoupling has come to the fore, with adoption of the Action Plan and launch of ERMA. Caught in the middle are the companies, who have largely been alone in trying to handle the opposition and discovering that social acceptance, equated with the social licence to operate concept for the purpose of this paper, is not only a result of their individual behaviour but also that of the entire industry. The Commission's convening of a stakeholder network to promote critical raw materials shows not only that government is willing to enter the fray but could be interpreted as an acknowledgement they see the legitimacy of the entire mining industry potentially at stake. 
What is happening on-the-ground is buttressed in recent academic literature asserting that while connected, there is a company social licence which is separate and distinct from the industry's social licence (Boutilier 2020). Research on the societal dimension of SLO, particularly around its preconditions, what drives it and how it affects community SLO, although the latter point still not well understood, acknowledges the importance of better understanding the societal influences on acceptance (Zhang et al. 2015; Litmanen et al. 2016; Zhang et al. 2018; Jartti et al. 2020; Poelzer et al. 2020; Ruokonen 2020). The concepts of societal SLO and industry SLO may either be mirroring or a response to conditions on-the-ground. What is clear is that policy, reality and research are converging as the acceptance of European mining has entered the discourse in all three realms.

Similar organizations and rationale invoked in the opposition against ERMA are also evident at the Member State level and at least three different approaches to address opposition have been attempted in Europe: two at the national level and one at the regional level. This paper compares the two national-level approaches, one in Finland and one in Spain, that not only address the opposition but also proactively seek to build societal SLO through the adoption of international good practices. Both Finland and Spain have adopted the same instrument for achieving acceptance, the Canadian Towards Sustainable Mining (TSM) program, yet have implemented it in very different ways. In Finland, the approach is a government-led network that includes representatives of all stakeholder groups with an interest in mining. All stakeholders are considered equal and decisions are made by consensus. In Spain, implementation is via an industry-led national standard through the UNE, the Spanish Standards Association, a more traditional and hierarchical style of implementation. The aim of this paper is to assess the effectiveness of the implementation mechanism on a policy instrument, in this case, whether a stakeholder network or a national standard is better suited to the implementation of an outside nation's industry standard. As both of these efforts are still new, this article endeavours to provide preliminary insights into the initial phase of adopting the TSM.

\section{Theory and literature review}

\section{Dialogue, relationship-building and trust in the con- text of societal SLO}

While the idea of societal SLO has always been embedded in the early academic SLO literature, only recently has it gained prominence. Owen and Kemp (2013) stress that the concept of SLO is applicable at different societal levels from the macro to the local. Prno and Slocombe (2012) write that SLO may be issued by society as a whole (e.g. government, communities, the general public, media), yet in a later study, Prno (2013) notes that while SLO can be issued by different elements and scales of society (e.g. communities, regions, and the general public), local communities are often a key arbiter in the process by virtue of their proximity to projects, sensitivity to effects and ability to affect project outcomes. Litmanen et al. (2016) surveyed several Finnish regions asking questions societal in scope addressing trust in national environmental legislation and attitudes toward the acceptability of the Finnish mining industry. Zhang et al. (2015) and Jartti (2020), conducting research in Finland and Australia, both assert the wider public has expectations regarding how the mining industry should act and conclude that acceptance is clearly mediated through trust, which suggests that building trust and SLO requires joint efforts by industry and government. Unlike the discussions around SLO at the community level between company and community, Zhang and Jartti's work not only validates the existence of SLO at the societal level but that government is a key actor. Recent research supports the government role (Lesser et al. 2020; Poelzer et al. 2020) as does real life in the case of ERMA's initiation by the European Commission.

In terms of understanding how to actually achieve societal SLO, the single most important factor that emerges in every study is trust in the mining industry (Thomson and Boutilier 2011; Prno and Slocombe 2012; Moffat and Zhang 2014; Suopajärvi et al. 2019). The question then becomes how to build trust in the mining industry among the public at large? At both the local and societal levels, engagement strategies emphasizing dialogue and relationship-building appear to be most successful (Prno 2013; Mercer-Mapstone et al. 2017a). The more positive an experience of dialogue is, the more likely the participants are to believe one another's actions are fair leading to stronger relationships that increasingly are built on trust (Mercer-Mapstone et al. 2018). However, when dialogue occurs without building relationships, it does not appear to flow through trust, suggesting there are specific types of dialogue that further acceptance (Mercer-Mapstone et al. 2017b). Indeed, this appears to be the case as MercerMapstone et al. (2017b) posit two types of dialogue, strategic and learning, where strategic is goal-oriented, and learning is about exchanging ideas and building relationships. Dialogue can also be destructive as their research indicates dysfunctional conflict can arise when the expectations around what a dialogue is supposed to achieve are not fulfilled (ibid 2017b). The connection between learning-based dialogue and relationships is crucial to both ensure that expectations are understood and met and that the process whereby an agreement is reached is considered fair. Governance literature also emphasizes the crucial role of communication and participatory approaches in perceptions of procedural fairness, as outcomes are more likely to be accepted if the process is deemed fair (Klijn and Koppenjan, 2016; Poelzer et al. 2020). 
As dialogue, relationship-building and trust are essential factors in building SLO at both community and societal levels, hypothetically, they should also play a significant role in the Finnish and Spanish implementation of the Canadian TSM. The implementation approach that more fully embraces the three factors should be more likely to achieve societal SLO. Figure 1 below visually illustrates these inter-relationships.

\section{The role of networks}

Delving into earlier literature on SLO, Thomson and Boutilier (2011) at the outset viewed communities as networks of stakeholder organisations. Equating communities with networks suggests that there is something inherent in the network structure itself crucial for SLO. The breadth of literature on networks is extensive, but there are two very different areas of researchnational security and network governance - that shed light on why and how networks are important in the SLO context.

Research on networks in the hard security context provides insights into the different ways they organize, the most important elements that must be in place to ensure their survival and the role that ideological beliefs play in not only determining who leaves and who remains, but why a common narrative that binds all participants is crucial. Structurally, they can assume three shapes: (1) a simple chain or line network where information moves along a line of separated contacts, (2) hub or star design where a set of actors is tied to a central but not hierarchical node and (3) an all-channel design or full-matrix, which is a collaborative network where everyone is connected to everyone else and there is no hierarchical decision-making (Arquilla and Ronfeldt 2001). The last type is the most difficult to run effectively yet has the highest potential for achieving goals, and the Finnish Network is an example. The authors

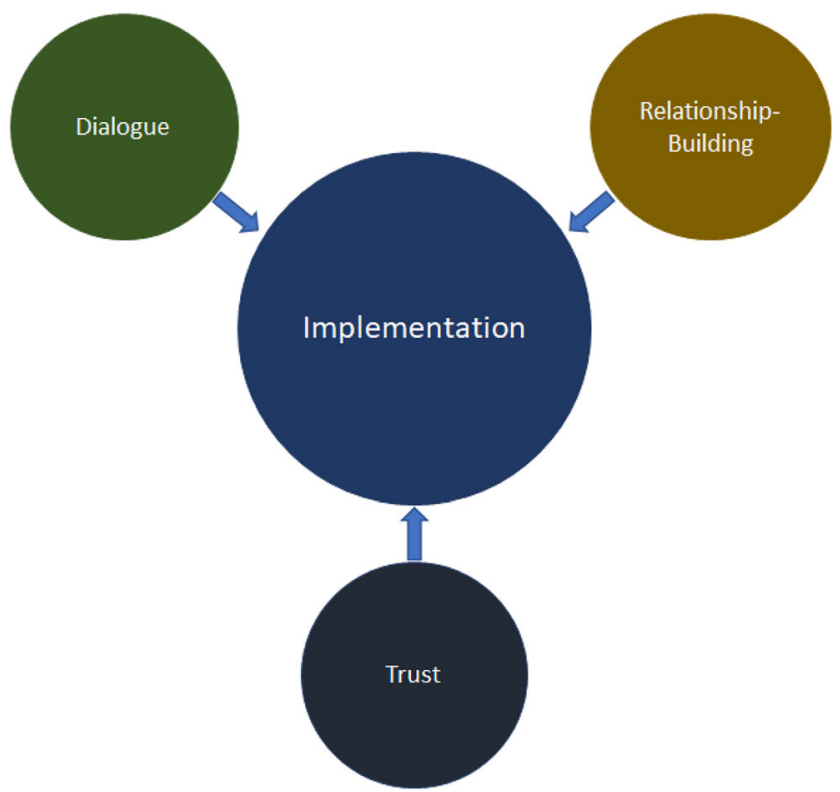

Fig. 1 SLO factors influencing implementation identify five levels of theory and practice crucial for a network's survival: technological (communication), social, narrative, organization and doctrine, and for an all-channel design network, having a strong narrative is the most important for its success and survival because it is the common purpose that connects members and draws new ones in. This assumes that a narrative internal to a network is the only one that is important. In the context of societal SLO, there is also a narrative external to the Finnish Network that needs to be crafted.

Networks coalesce not only to achieve a particular end but are also a form of governance (Klijn and Koppenjan 2016) and one particularly suited to solving the problems inherent in a complex society. As opposed to traditional top-down approaches, networks are horizontal, consensus-based and usually long-term voluntary engagements, and similar to SLO, they are in need of trust-building efforts. Revisiting the idea of process versus outcome, because networks are consensusbased bringing stakeholders together to dialogue and solve problems, in so doing, agreements reached may be more durable and implementable by taking more interests into account, and the agreement is also more likely to be fair and perceived as fair. There are, however, other views about consensual processes that are not so positive. Tewdwr-Jones and Allmendinger (1998), writing in the context of planning theory, believe that consensus is a completely utopian idea in political arenas as there will always be winners and losers. Although created to solve complex problems, Klijn and Koppenjan (2016) acknowledge that networks themselves are inherently complex because each participant has their own perception of problems and solutions, which can lead to substantial differences in perceptions, value conflicts and disagreement about outcomes. Yet outcomes in a network structure may not be the only, or even the main, desirable outcome as the intangibles such as new relationships, new practices and new ideas may be seen as more important (Innes and Booher 1999).

\section{National standards}

As opposed to the non-hierarchical network structure, the process of adopting national standards is one that is traditional and top-down albeit with a public consultation component. Similar to the network, however, the development of standards is voluntary and decisions are reached through consensus. Whether they are formal (national, regional and international) or informal standards, it is the community of stakeholders comprising the membership of the standards organization that decides what standards should be developed, what they should contain and when and how they should be published (European Commission 2013). The basic structures and processes for adopting formal standards are supposed to offer unrivalled vigour and transparency, if not to the outside world, at least to the members involved. 
Standards are also voluntary to implement and are meant to provide the private sector with clear and definitive ways of naming, describing and specifying, measuring and testing, as well as managing and reporting an action (European Commission 2013). They provide a recognized means for assuring the quality and reliability of processes and therefore help bestow legitimacy on outcomes. Implementation of a standard's objectives is typically benchmarked and measured through the use of indicators. Once the standard is adopted, its implementation is not typically overseen by the standards body but by the entity leading the effort (European Commission 2013). Certification programs are often attached to standards and can therefore also act as a branding mechanism. In the Spanish case, AENOR is responsible for the certification scheme attached to the UNE Standards and the entire UNE Standard must be implemented for a company to receive certification (Industry A, personal communication, November $23,2020)$. There is also a cost associated with the certification.

As a form of soft-regulation, the benefit of standards is that they provide a company/industry with a clear method for achieving a consistently good outcome, and therefore, standards also are of tangible benefit to stakeholders. To the extent the public is aware of, and has confidence in standards, they should also help improve the image of a company/industry and can be a form of branding. While the process of creating networks and standards are very different, the objectives of ensuring a process acceptable to all, both those involved and broader society, and thus an outcome accepted by all, are the same.

\section{Research hypothesis and methods}

The multi-stakeholder network governance approach infuses trust-building measures among all representative interests at the beginning and throughout a process, whereas adopting national standards waits for societal trust to come only once companies implement, in this case, the Canadian TSM program. The hypothesis of this paper, therefore, is that the network approach in Finland is more likely to result in a better implementation of the TSM and hence have a higher likelihood of achieving and maintaining societal SLO. In short, it is expected to improve the framework conditions for implementation and thus support the delivery of better outcomes (Tewdwr-Jones and Allmendinger 1998; Innes and Booher1999; Gugerell et al. 2020).

The data was collected in the course of the H2020 MIREU (Mining and Metallurgy Regions EU) project in several stages. First, a PEST (political, economic, socio-cultural and technical) analysis was conducted across nine of the MIREU partners regions: Andalusia and Castilla y Leon in Spain, Cornwall in the UK, Lapland in northern Finland, Saxony in Germany, Sterea Ellada in Greece, Styria in Austria and both
Upper and Lower Silesia in Poland in order to map background conditions that influence SLO in the regions. The PEST identified several instances where acceptance of the mining industry was supported by government: two at the national level and one at the regional level. The two national efforts are the Finnish Network for Sustainable Mining (Finnish Network) and the UNE Standards for Sustainable Mining (UNE Standards), with a focus on the most recent inclusion into one of the standards - the Communities of Interest Protocol from the Canadian TSM program.

To gain insight into the origins of the Network and UNE Standards, how they were developed and the expectations around what they should achieve, interviews with key people involved in their creation, development and implementation were conducted in 2019. In Finland, interviews were conducted during Autumn 2019 and included eight participants highly involved in the Network. In Spain, the interviews were conducted also during Autumn 2019 and included five persons closely engaged with initiating and adopting the UNE Standards, and the Communities of Interest Protocol (COI) in particular, as this is both the most recent addition and the one that focuses on stakeholder engagement. It should be noted that since the COI was adopted only in 2019 , there are no questions asking about its implementation, rather only what implementation is anticipated to look like and achieve.

\section{Government-led network vs industry-led national standard}

\section{The Finnish Network for Sustainable Mining}

Finland takes a collaborative approach to implement trustbuilding measures through the establishment of an informal network of stakeholders with an interest in working together to ensure a responsible Finnish mining industry. The catalyst for the Network's establishment in 2014 was the mining disaster at Talvivaara in October 2012. Although initially dubbed 'the miracle of Sotkamo' in the media, due to growing concerns over rising contaminants in the wastewater, by early 2012, the public image changed from a blessing into a curse (Sairinen et al. 2017). By the time the mine's gypsum sediment pond leaked in November 2012, public outrage and criticism was massive. It was a process which began as a local environmental conflict but over time became a symbol of national conflict in the mining industry (Sairinen et al. 2017). Research at the time (Suopajärvi et al. 2017) showed that all actors along the permitting chain, not just industry, were evaluated as a result of the accident. Industry, politicians and governmental authorities realized that the public trust in both the mining industry and the government was in peril (Jartti et al. 2017). 
The Network was based on previous stakeholder meetings resulting from the Talvivaara disaster when the Ministry of Employment and the Economy, together with the Ministry of Environment, brought together representatives from the extractive industry and its stakeholders to chart a path forward. Establishing a Network for Sustainable Mining based on industry self-regulation, inclusive of all stakeholders and with a mandate to avoid and/or solve conflicts became a primary goal (Kaivosvastuu 2015). Sitra, the Finnish Innovation Fund, funded the Network for its first 2 years, but thereafter, it would have to be financially self-sustaining. In May 2014, the Network was formally established, composed of the stakeholder groups shown in Fig. 2, and eventually adopted the Finnish Toward Sustainable Mining Standard based primarily on the Canadian TSM but also on the environmental section of IRMA (Initiative for Responsible Mining Assurance) (Kaivosvastuu 2015). Two protocols were added to the Canadian TSM, water management and mine closure, and associated tools were developed to aid in implementation, such as the Corporate Social Responsibility report, toolboxes for exploration and exploitation and online training courses.

Although almost all stakeholder groups with an interest in mining are represented in the Network, the industry most opposed to mining, tourism, has never joined even though the Network repeatedly attempted to bring them on board (Civil Society A, personal communication, August 27, 2018). The membership has remained relatively stable over the past 5 years as Table 1 shows, but there have been some changes with 2015 being a particularly momentous year as Sitra withdrew its financial support from the Network and it moved under the Finnish Mining Association (FinnMin), the Permanent Secretary of the Ministry of Environment assumed the chairmanship and the Finnish Sámi Parliament withdrew its formal membership.

With the Finnish TSM Standard adopted and the accompanying tools developed by the Network, it now is up to the companies to each begin implementing the protocols, complying with the indicators and reporting on the outcomes. There is little public information on how the actual implementation is proceeding, but Ruokonen (2020) recently conducted a study using an online questionnaire sent by email to 51 persons in managerial positions representing 15 mining companies. In total, 36 responses were received, and among those, $81 \%$ of the respondents stated they are going to implement the Mining Standard, $8 \%$ of the respondents have implemented, $56 \%$ have started to implement and $17 \%$ have not yet started to implement them (ibid 2020).

\section{UNE Standards for Sustainable Mining Management}

In Spain, the Canadian TSM is also the instrument adopted to build public trust in the mining industry; however, implementation is very different than in Finland as it is an industry-led national standard. This approach emphasizes trust-building between communities and companies at a later stage once the companies begin following the procedures laid out in the UNE Standards.

The vehicle for implementing the Canadian TSM is the Spanish Association for Standardization (UNE), a quasigovernmental entity designated by the Spanish Ministry of Economy, Industry and Competitiveness to the European Commission. The UNE is responsible for the development and adoption of all national standards. Integration of the Canadian TSM into the Spanish UNE Standards began in 2008 first with the environmental and management protocols becoming UNE 22470 Sustainable Mining Management Systems (Requirements) and UNE 22480 Sustainable Mining Management Systems (Indicators). Both standards were later revised in 2015 and in 2019. In the latest revision (2019), UNE 22470 was renamed the Sustainable Mining, Mineral Processing, Metallurgy Management System (Indicators) and UNE 22480 as Sustainable Mining, Mineral Processing, Metallurgy Management System (Requirements). All UNE standards are produced by committees that operate

Fig. 2 The structure of the original multi-stakeholder network of the Finnish Network for Sustainable Mining (YrjöKoskinen 2015)

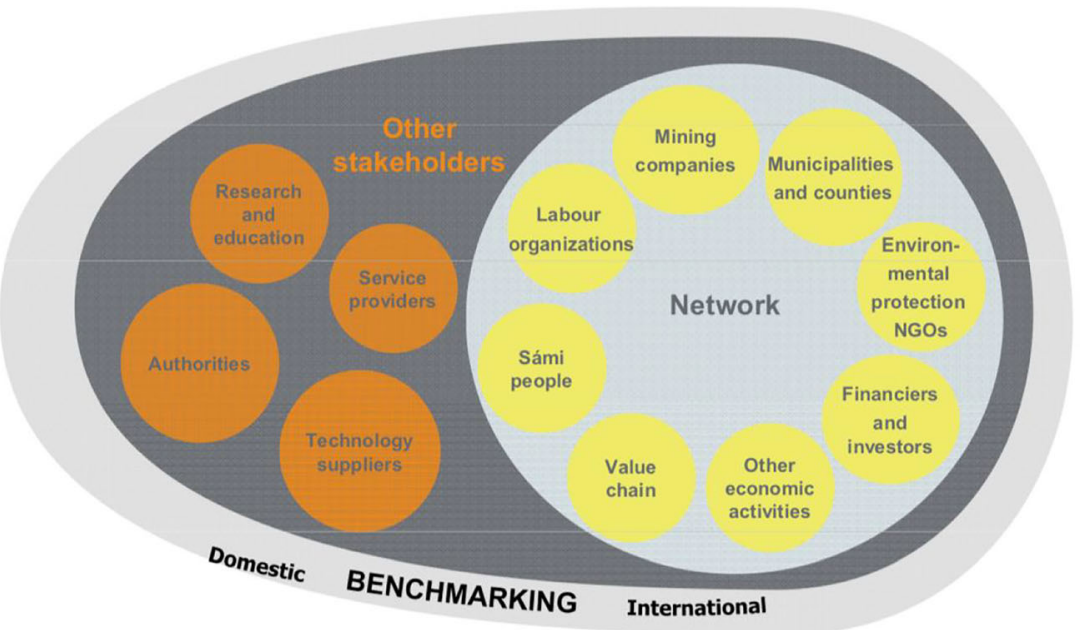


under a well-defined procedure. CONFEDEM, the National Confederation of Mining and Metallurgy Enterprises, is the President of the Technical Committee 22 Mining \& Explosives (CT22), where its Subcommittee 3 (CT22-SC3) is dedicated to Sustainable Mining Management (Industry B, personal communication, February 18, 2019). The Sustainable Mining Management sub-committee consists of 30 people and includes a wide array of stakeholders ranging from administration, civil society, companies, associations and UNE officers, who are present in all Committee meetings to ensure there is coordination between committees (Industry B, personal communication, April 23, 2019). Once a draft of the standard is approved, there is a public consultation for two months. The comments received are analysed, answered and included if accepted. UNE then sends it to the Spanish Official Bulletin when it is then considered an official Spanish Standard.

Although sustainable mining standards existed since 2008, research in the MIREU project showed that opposition to mining activities in Spain continued to increase after 2008. Realising that current efforts to operate more sustainably were not enough, CONFEDEM spearheaded the effort in 2018 to also adopt the Canadian TSM Aboriginal and Community Outreach Protocol renaming it the Communities of Interest (COI) Protocol. When the COI was proposed to the membership, unanimous approval was given for its adoption indicating acknowledgement by the Spanish mining industry that communication with stakeholders needed improvement and also indirectly validating the UNE process and method for implementation of the TSM (Industry B, personal communication, May 2, 2019). In 2019, the COI was incorporated into UNE 22470:2019.

\section{Results}

Finland and Spain have the same goals and objectives, to build public trust in the mining industry and achieve societal SLO; however, their choice of implementation differs dramatically. Since both the Finnish Network and the UNE Standards are still in the early stages of implementation, with the COI having only been adopted in 2019 , the results provide only preliminary insights into the initial phase of adopting the TSM. To connect the two approaches with societal SLO, a revisit of the SLO literature discussed earlier that focuses on trustbuilding is warranted. The work of Mercer-Mapstone et al. (2018) in particular provides an empirical basis for linking dialogue and relationships with trust. Hence, the interviews are analysed from the perspective of whether the Finnish Network and UNE Standards are perceived to contribute to dialogue, relationship-building and trust and therefore whether one or the other is better suited to achieve and maintain societal SLO. 


\section{Dialogue}

One of the major accomplishments of the Network that all interviewees emphasized is its ability to promote an open, active dialogue within a safe space. Consensus-based decision-making also had a positive effect as voices were not perceived as being marginalized. People with different viewpoints came together and most eventually agreed on the way forward. Those that did not left the Network (see Table 1). This reveals both the positive and negative aspects of a network governance approach: positive since dialogue encouraged learning and perhaps even contributed to the shifting of viewpoints allowing for compromise (MercerMapstone et al. 2018) and negative because those who politically found it challenging to accept a solution that advocated mining, albeit responsible mining, felt compelled to leave. Now that the Finnish TSM Standard and accompanying tools have been developed, the companies must implement the standard. Momentum appears to be ebbing as the main purpose of the Network has been fulfilled. There is less need for dialogue in general, and for the learning type of dialogue in particular, as the future work is not oriented to solving problems but to monitoring companies. While the internal dialogue early on was robust and positive, all of the interviewees felt the dialogue with external stakeholders was lacking. Suggestions for improvement include that the Network should better communicate its activities, especially the benefits of the liability standards, have more visibility, proactively engage external stakeholders and, in the words of one interviewee, be more present and visible as one front (Landowner-FI1).

In Spain, the UNE has a hierarchy of technical committees and a clear order of processes that are oriented toward transparency, consensus and inclusion; yet, there is no information as to the nature of the internal dialogue. As there were approximately 30 stakeholders representing different interest groups involved in the adoption of the COI, there must have been dialogue and one can only speculate this would likely have been strategic as the goal was to integrate the protocol from Canada into the existing UNE Standard and not to debate whether it should be integrated. Along with trust, meaningful dialogue with stakeholders appears to be something intended as an outcome of the UNE Standards rather than part of the process. The interviews themselves shed light on this as the only discussion around dialogue centres on communication between companies and stakeholders in the context of a project. Among those interviewed in Spain, all agreed that the biggest problem between industry and communities is the lack of communication:

For sure, communication with stakeholders is the absolute and necessary base for any industrial project, mining and exploration even more (Industry-SP1).

Yet others expressed concern that more community engagement may result in unmet expectations and cause more problems.
The COI could have a negative outcome if data is not well explained to communities (Administration-SP1).

There is reticence to communicate because of a fear, if done poorly, it will cause more problems. The less risky course to take, in the eyes of many companies, is not to engage. However, it is becoming more and more obvious that some communication is necessary so having clear rules and a systematic communication procedure is believed to make it safer and easier for companies.

Thanks to the COI, each company will have a systematic way to identify stakeholders and communicate with them (Industry-SP2).

Perhaps the uncertainty around outcomes in dialogue has also subtly influenced the way in which Spain has chosen to implement the TSM. In Finland, while there is hesitation by some of the companies to implement the Finnish Standard, the reasons given were not due to concern over poor communication outcomes, but rather more from a cost perspective. Whether this outlook by the Finnish companies is due to the effectiveness of the network structure in building early support for the TSM is unclear, but there does appear to be a more pervasive sense in Spain that dialogue, in general, is fragile and could be harmful as well as beneficial.

\section{Relationship-building}

The multi-stakeholder approach to building the Network encouraged the interaction of people who might not otherwise speak with one another. Entities both for and against mining participated from its inception with the exception of the tourism industry and relationships between the members appeared to be strong, especially at the inception.

\section{It has created a great forum for cooperation and several useful tools including the Protocols and those for reporting (Industry-SP1).}

With the inclusion of stakeholders opposed to mining, the Permanent Representative of the Ministry of the Environment as the chair of the Finnish Network, and the former Executive Director of FANC appointed as Director General, the Network was initially viewed not as a mining association but representative of all interests. At least among the stakeholder groups involved in mining, the Network enjoyed a high degree of legitimacy, and through the Network participants, the bonds between the groups themselves also appeared to grow stronger as there was great momentum and much accomplished the first two years. One setback occurred in the first year of the Network moving under the Finnish Mining Association (FinnMin) with the departure of the Sámi Parliament, who 
indicated that it was politically difficult to remain. As discussed previously, the narrative of a collaborative network is important, and this departure, coupled with the tourism industry having never joined, is an example where not everyone shared the narrative that mining should go forward. While the Network increased interaction and built solid relationships with stakeholders within the Network, relationship-building did not extend outside of the Network and is only expected to as an outcome of companies implementing the Finnish TSM Standard.

For Spain, there is little information about relationships being built as part of adopting the Canadian TSM protocols as UNE Standards. While there were public consultations and it was a multi-stakeholder process to approve the standard, there is no indication that relationship-building was part of the process. Relationship-building is also something anticipated to occur as an outcome of implementing the UNE Standards and the COI in particular.

\section{Trust}

The Network is seen as neutral and trustworthy by all of those interviewed because it was initiated by government, brought all of the relevant stakeholders together, operated on the basis of consensus to decide how to achieve acceptance of the mining industry and developed the Finnish TSM Standard and accompanying tools. Reflective of the relationships built between participants and the belief in what they were doing, there was unanimous agreement that:

\section{The Network is a tremendous achievement that should continue as it is a unique forum in which stakeholders can come together and engage in meaningful dialogue as well as actively influence the behaviour of the Finnish mining industry (Research-FI1).}

The interviews reveal a divide as to whether the Network continues to fairly represent all interests given the exit by several stakeholders. While trust among members remains very high, responses indicate a concern that those outside of the Network may not see it as representative, even though it continues to include the Reindeer Herders Association, FANC and WWF, and therefore, trust-building with the public will be compromised.

The greatest risk is the lack of commitment of the stakeholder and parties. The network is as strong as its partners, meaning if they leave, there's no network (Civil Society-FI1).

While some are questioning whether they should continue in the Network, most of the original members have remained and are still very positive about the Network continuing to further the acceptance of the mining industry. However, because the Network remains largely invisible to people outside those with an active interest in mining, trust-building with society at large will still need to be an outcome of companies implementing the standards and over time demonstrating they are a responsible industry.

Although the UNE is considered trustworthy by industry and the public alike, the process of deciding whether to integrate the Canadian TSM as a UNE Standard occurred via a more traditional, hierarchical mechanism with a limited group of stakeholders. The interviews do not indicate that trustbuilding was part of the process; hence, societal trust and acceptance would be an outcome of industry's implementation. However, industry could have chosen to integrate the TSM into a professional association such as CONFEDEM, as Finland did moving the Network under FinnMin, but they did not and instead chose to make it a national standard suggesting it was important that an external entity imbued with societal trust confer legitimacy on it. In addition, the UNE is an established body unlike the Network, which is a voluntary organisation that must fund itself. Perhaps if sentiments such as the following were visible to the public, it would result in heightened trust:

\section{Mining companies must demonstrate technical and eco- nomic capabilities to develop a mining project so it is logical to recognize their capacity to involve the COI to solve acceptance problems (Industry-SP3).}

The lack of public visibility or understanding of what industry is committing to is one obstacle to societal SLO:

There is scarce acknowledgement by the public and weak support from the Administration (Industry-SP4).

This comment also notes the lack of support by the national government. In part, this is due to mining being a regional competence in Spain, but there is also an issue with the national government being uninterested in the UNE Sustainable Mining Standards because they do not support existing legislation but aim for something higher. If there is no direct connection with legislation, the interviewees all indicated the national government tends to be uninterested. Achieving societal SLO without the support of the national government lays a heavy burden on industry but also on the regional administrations.

\section{Discussion}

The premise of this paper is that dialogue, relationshipbuilding and trust are essential for achieving and maintaining societal SLO; therefore, an approach, which incorporates 
these factors, should have a good chance at fulfilling the objective. Finland and Spain both share the same objective, to build trust between the public and their respective mining industries and achieve societal SLO. The Finnish Network early on engaged in a constructive, learning-oriented dialogue that contributed to the building of strong relationships which resulted in a great deal of trust among its participants.

\section{The Network was a great achievement by the Finnish society and it is hoped that it would continue being active and well-supported (Research-FI2).}

Its focus on engaging all stakeholders, supportive of mining or not, to chart a path forward together has been the core of its work. Trust-building is both part of the process and an anticipated outcome. The tangible benefits, such as participants learning from and establishing relationships with people that have opposing views and also the international visibility of the Network and its being touted as an exemplary model of cooperation, come from the existence of the Network itself, while the benefits resulting from implementation of the Finnish TSM Standard remain unclear.

To some degree, the Network has been a prisoner of its own success as its early achievements raised expectations that mining would soon be accepted across Finland. Over time, the mandate of the Network shifted from creating something new to ensuring the continued responsible behaviour of companies. However, implementation of the Finnish TSM by member companies is slow and public opposition to mining continues to grow raising concerns about the effectiveness of the Network. Dialogue and relationship-building must be scaled-up and occur between Network members and the public at large now.

Spain has been more focused on what the standards represent and what they may accomplish looking at trust-building as an outcome. To some extent, the hierarchical nature seemed to appeal at least to the mining industry as the UNE provides a clear, assured process both for integration of the Canadian TSM and its implementation. The Spanish approach has an advantage over the Finnish Network in that it is a wellestablished organization that is not in danger of ceasing to exist. Since the Finnish government is not financially supporting the Network, and it must be self-sustaining, there is a real possibility the Network could disintegrate. As the Network, even more than the TSM Standard, has furthered trust among stakeholders with an interest in mining, its disintegration would be both a symbolic and figurative blow to the efforts of building societal SLO.

In Spain, companies appear hesitant to implement the UNE Sustainable Mining Management Standards because they are perceived as too costly and onerous in terms of data collection (there are more indicators in UNE than ISO) and their benefits are as yet unproven. There is also no separate certification for the COI, the whole UNE 22470:19 Standard needs to be implemented in order to obtain certification and it contains roughly 56 indicators. This in combination with the standards being voluntary, as one individual notes, makes implementation difficult:

\section{If it is not required by law, it would be more difficult to engage companies (Administration-SP1).}

The Finnish Network, in contrast, included exploration and mining companies from its inception, so industry was instrumental in the decision to adopt the Canadian TSM and also helped design the implementation tools. Companies needed no convincing that the Finnish TSM was both the right solution and would be of benefit to them if implemented.

In Spain, mining companies need to view the utility of UNE as high and that social priorities matter as much as economic ones. Yet, this appears some way off as one individual notes:

The majority of companies are still reluctant to talk about transparency and communication (Industry-SP3).

Because of the hesitancy, the success of the COI appears fragile:

This is a Standard and its power is based on confidence. It is contingent on how genuinely willing companies are to implement the COI in the way it is intended (IndustrySP5).

Willingness to implement and the ability to implement are two different things, however. Communication that is both clear and empathetic is a skill, and like all skills, it needs to be learned. One of the benefits of the Network is that because participants regularly interacted exchanging views and problem solving together, they learned how to communicate about issues that were difficult and emotional with those of like minds and unlike minds, for example, what words and phrases work, which ones do not work and if there are sensitivities to pay attention to. This is a different type of learning than what was discussed earlier as this dialogue process involves learning on many levels, substantively, but also simply how to speak and listen to one another in a positive way and stay committed through difficult times.

Learning to communicate with people who have opposing views and working through the difficulties to resolve a problem was not part of the adoption process of the COI. As Mercer-Mapstone et al. (2017b) notes, dysfunctional communication will likely make situations worse, and it is understandable that the geologists and engineers on the ground would feel uncomfortable engaging in situations that could be negative. Without dialogue in this context, relationshipbuilding and trust are not possible. 
One of the surprising results is that while a network governance approach should be more likely to achieve and maintain societal SLO, this is not necessarily the case. The effectiveness of the Finnish Network depends on several factors: whether its narrative is a deeply held belief binding participants together in a common cause, its ability to be selfsustaining and its visibility to the broader society. Trust- building measures built into the process will always have positive results, but whether those results contribute to the desired outcome is not guaranteed.

The mining industry in Spain has more of an uphill battle. Garnering acceptance is left to the companies. With mining being a regional competence, the national government appears to have little interest in supporting
Table 2 Comparing networks and national standards

\begin{tabular}{|c|c|c|c|c|}
\hline & Purpose & Implementation & Beneficiaries & 3 SLO factors \\
\hline Networks & $\begin{array}{l}\text { Encourage dialogue, } \\
\text { relationship- and } \\
\text { trust-building } \\
\text { internally to reach a } \\
\text { consensus-based } \\
\text { outcome. }\end{array}$ & $\begin{array}{l}\text { The company's } \\
\text { responsibility } \\
\text { with oversight by } \\
\text { a neutral party } \\
\text { appointed by the } \\
\text { Network. }\end{array}$ & $\begin{array}{l}\text { The Network includes } \\
\text { representatives of } \\
\text { most stakeholder } \\
\text { groups in Finland } \\
\text { with an interest in } \\
\text { mining. Those in } \\
\text { the Network } \\
\text { benefit by being } \\
\text { involved in the } \\
\text { process, and } \\
\text { society (and } \\
\text { industry indirectly) } \\
\text { should benefit once } \\
\text { the companies } \\
\text { implement the } \\
\text { TSM. }\end{array}$ & $\begin{array}{l}\text { Dialogue: 'Learning' } \\
\text { dialogue forms the } \\
\text { basis of } \\
\text { relationship-- } \\
\text { building. This only } \\
\text { goes so far though } \\
\text { and cannot } \\
\text { overcome } \\
\text { fundamental values. } \\
\text { Relationship-building: } \\
\text { Among participants, } \\
\text { relationship-- } \\
\text { building keeps pace } \\
\text { with learning and } \\
\text { appears to plateau } \\
\text { once learning stops. } \\
\text { Trust: Companies are } \\
\text { more likely to } \\
\text { implement the TSM } \\
\text { but societal trust and } \\
\text { SLO ultimately } \\
\text { depend on how well } \\
\text { it is implemented. }\end{array}$ \\
\hline $\begin{array}{l}\text { National } \\
\text { Stand- } \\
\text { ard }\end{array}$ & $\begin{array}{l}\text { Provide a systematic } \\
\text { procedure and } \\
\text { objective indicators } \\
\text { for the private } \\
\text { sector to implement } \\
\text { good practices } \\
\text { which results in a } \\
\text { reliably good } \\
\text { outcome. }\end{array}$ & $\begin{array}{l}\text { The company's } \\
\text { responsibility } \\
\text { with oversight } \\
\text { likely at the } \\
\text { regional or even } \\
\text { provincial level } \\
\text { in Spain. }\end{array}$ & $\begin{array}{l}\text { As industry led the } \\
\text { development of the } \\
\text { standards, } \\
\text { reputationally they } \\
\text { should benefit at } \\
\text { least among those } \\
\text { involved. The } \\
\text { benefits are seen } \\
\text { once the companies } \\
\text { implement the } \\
\text { standards and } \\
\text { improve their } \\
\text { engagement. }\end{array}$ & $\begin{array}{l}\text { Dialogue: 'Strategic' } \\
\text { dialogue among } \\
\text { those engaging in } \\
\text { the UNE Standard } \\
\text { development is the } \\
\text { norm. } \\
\text { Relationship-building: } \\
\text { Although involving } \\
\text { multiple stakeholder } \\
\text { groups, adopting the } \\
\text { TSM was the shared } \\
\text { goal of all. There } \\
\text { was no need to build } \\
\text { strong relationships } \\
\text { because the } \\
\text { outcome was } \\
\text { desired and } \\
\text { pre-ordained. } \\
\text { Trust: Many mining } \\
\text { companies see little } \\
\text { utility in the UNE } \\
\text { Standards. Societal } \\
\text { trust and SLO } \\
\text { ultimately depend } \\
\text { on TSM } \\
\text { implementation. }\end{array}$ \\
\hline
\end{tabular}


mining-related activities. Legislation and regulation, as well as future oversight of the COI, depend on the regions. The option of a national government-led network bringing stakeholders together is logistically challenging, and given the present governance structure, extremely difficult. Having an industry-initiated national standard that seeks to improve societal trust through developing better dialogue and relationships both with communities and society is, for now, one of the only options available for moving forward. Although a national standard is a more traditional, hierarchical approach that leverages its success on outcomes, the process of adoption is transparent and inclusive. The potential desired outcome is more fragile and finely poised than the network governance approach, but it is still possible.

Table 2 below compares how dialogue, relationshipbuilding and trust are achieved in a network versus a national standard.

In summary, the lessons for networks and societal SLO are the following:

- Learning oriented dialogue, relationship-building measures and a shared narrative must be central to the internal functioning of a network when it first begins and must remain so throughout its existence. However, depending on its purpose, the network may need to shift its focus outward and apply these trust-building measures to groups external to the network, or in the case of the Finnish Network, to society at large.

- Networks, especially those involved in bringing stakeholders together on contentious issues, should be representative of all interests throughout its existence. Trustbuilding outside the network is particularly sensitive to perceptions of legitimacy and fairness.

- Fulfilling the purpose of a network is crucial throughout all its phases. In Finland, the initial purpose of establishing a network and charting a path forward to ensure a responsible mining industry was fulfilled. However, the purpose of actually demonstrating to society that when industry follows the Finnish TSM, mining can be conducted responsibly and respectfully has not yet been fulfilled because of the lengthy implementation phase. This lag points to the limits of self-regulation rather than its benefits and decreases rather than increases societal trust.

Because the COI is so new and there is no information on implementation, the lessons learned are confined to those for networks. However, the Spanish mining industry could learn from the Finnish Network's successes and mistakes as it must now embark on its own journey to build trust through dialogue and relationship-building among the Spanish populace.

\section{Conclusion}

Two European countries with a desire to promote more responsible mining and achieve societal SLO each independently arrived at the conclusion that adoption of the Mining Association of Canada's TSM program would be the best way forward. Finland chose a government-led network to implement the program whereas Spain chose an industry-led national standard. The first includes trust-building measures as part of the process of deciding what instrument to adopt as well as its implementation, whereas the second relies on trustbuilding only as an outcome of implementation. While dialogue, relationships and trust are essential for societal SLO, and building them into a process and outcome should produce a better chance of attaining societal SLO than only building them into an outcome, the example of the Finnish Network shows the difficulties in maintaining dialogue, relationships and trust over time. Whether integrating them into a process results in a better outcome is not clear if they begin to be excluded from the process.

While Finland and Spain both assume the path to societal SLO is by way of building trust between industry and society, at least in Europe, it is not clear that the path to societal SLO is solely the adoption of international good practices, because neither the Network nor the national standards approach, at least so far, indicates an increase in acceptance. Although these are preliminary findings since there is little information on the Finnish implementation and none on the Spanish, what appears to be the case is that industry alone cannot garner societal SLO. It must be a joint effort between society, industry and government to engage in a continuous dialogue that over time will lead to relationship-building and trust.

Acknowledgements A special note of thanks goes to the members of the Finnish Network for Sustainable Mining and CONFEDEM for their generous time and insights. Many thanks as well to the MIREU partners at GKZ Freiberg for their patience, diligence and tremendous efforts. And last but certainly not least, my heartfelt thanks to the reviewers, whose comments made all the difference in the world.

Funding Open access funding provided by University of Lapland. This work was supported by the H2020 Project MIREU, funded by the European Union's Horizon 2020 research and innovation programme (grant number 776811/Topic: SC5-15-2016-2017).

Open Access This article is licensed under a Creative Commons Attribution 4.0 International License, which permits use, sharing, adaptation, distribution and reproduction in any medium or format, as long as you give appropriate credit to the original author(s) and the source, provide a link to the Creative Commons licence, and indicate if changes were made. The images or other third party material in this article are included in the article's Creative Commons licence, unless indicated otherwise in a credit line to the material. If material is not included in the article's Creative Commons licence and your intended use is not permitted by statutory regulation or exceeds the permitted use, you will need to obtain 
permission directly from the copyright holder. To view a copy of this licence, visit http://creativecommons.org/licenses/by/4.0/.

\section{References}

Arquilla J, Ronfeldt D (2001) Networks and netwars: the future of terror, crime, and militancy. RAND Corporation, Santa Monica, California. https://www.rand.org/pubs/monograph_reports/ MR1382.html. https://doi.org/10.7249/MR1382

Boutilier R (2020) From metaphor to political spin: understanding criticisms of the social licence. The Extractive Industries and Society.: 100743. https://doi.org/10.1016/j.exis.2020.05.022

Civil Society open letter (2020) Civil society concerns on EU critical raw materials plans. https://friendsoftheearth.eu/publication/civilsociety-concerns-eu-critical-raw-materials-plan/

European Commission (2013) Standards and standardisation: a practical guide for researchers. Publications Office of the European Union, Luxembourg

European Union: European Commission, 2008 Communication from the Commission to the European Parliament and the Council on The raw materials initiative - meeting our critical needs for growth and jobs in Europe, $\operatorname{COM}(2008) 699$ final, available at https://eur-lex. europa.eu/legal-content/EN/TXT/?uri=CELEX:52008DC0699 [accessed 14 January 2021]

European Union: European Commission, 2020 Communication from the Commission to the European Parliament, the Council, the European Economic and Social Committee and the Committee of the Regions on Critical Raw Materials Resilience: charting a path towards greater security and sustainability, $\operatorname{COM(2020)} 474$ final, available at: https:/www.politico.eu/wp-content/uploads/2020/09/ Communication-Critical-Raw-Materials-Resilience.pdf [accessed 11 January 2021]

Gugerell K, Endl A, Gottenhuber S, Ammerer G, Berger G, Tost M (2020) Regional implementation of a novel policy approach: the role of minerals safeguarding in land-use planning policy in Austria. Extr Ind Soc 7(1):87-96. https://doi.org/10.1016/j.exis.2019.10.016

Innes J, Booher D (1999) Consensus building and complex adaptive systems: a framework for evaluating collaborative planning. JAPA 65(4):412-423

Jartti T, Litmanen T, Lacey J, Moffat K (2017) Finnish attitudes toward mining: citizen survey-2016 results. YFI Publications 4. University of Jyväskylä. Available at https://jyx.jyu.fi/handle/123456789/ 56561/ [accessed 7 April 2020]

Jartti T, Litmanen T, Lacey J, Moffat K (2020) National level paths to the mining industry's Social Licence to Operate (SLO) in Northern Europe: the case of Finland. Extr Ind Soc 7:97-109. https://doi. org/10.1016/j.exis.2020.01.006

Kaivosvastuu (2015) Success through dialogue: annual report of the network for sustainable mining 5/2014-5/2015. Helsinki, Network for Sustainable Mining

Klijn E, Koppenjan J (2016) Governance networks in the public sector. Routledge, New York

Lesser P, Gugerell K, Poelzer G, Hitch M, Tost M (2020) Europe and social license to operate. Extr Ind Soc. https://doi.org/10.1016/j.exis. 2020.07 .021

Litmanen T, Jartti T, Rantala E (2016) Refining the preconditions of a social licence to operate (SLO): reflections on citizens' attitudes towards mining in two Finnish regions. Extr.Ind.Soc. 3:782-792. https://doi.org/10.1016/j.exis.2016.04.003

Mercer-Mapstone L, Rifkin W, Louis W, Moffat K (2017a) Meaningful dialogue outcomes contribute to laying a foundation for social licence to operate. Resour. Policy 53:347-355. https://doi.org/10. 1016/j.resourpol.2017.07.004

Mercer-Mapstone L, Rifkin W, Moffat K, Louis W (2017b) Conceptualising the role of dialogue in social licence to operate. Resour. Policy 54:137-146. https://doi.org/10.1016/j.resourpol. 2017.09.007

Mercer-Mapstone L, Rifkin W, Louis W, Moffat K (2018) Companycommunity dialogue builds relationships, fairness, and trust leading to social acceptance of Australian mining developments. J. Clean. Prod 184:671-677. https://doi.org/10.1016/j.clepro.2018.02.291

Moffat K, Zhang A (2014) The paths to social licence to operate: an integrative model explaining community acceptance of mining. Resour. Policy 39:61-70. https://doi.org/10.1016/j.resourpol.2013. 11.003

Owen J, Kemp D (2013) Social licence and mining: a critical perspective. Resour. Policy 38:29-35. https://doi.org/10.1016/j.resourpol.2012. 06.016

Poelzer G, Segerstedt E, Beland Lindahl K, Abrahamsson L, Karlsson M (2020) Licensing acceptance in a mineral-rich welfare state: critical reflections on the social license to operate in Sweden. Extr Ind Soc 7(3):1096-1107. https://doi.org/10.1016/j.exis.2020.05.008

Prno J (2013) An analysis of factors leading to the establishment of a social licence to operate in the mining industry. Resour. Policy 38: 577-590. https://doi.org/10.1016:j.resourpol.2013.09.010

Prno J, Slocombe D (2012) Exploring the origins of 'social license to operate' in the mining sector: perspectives from governance and sustainability theories. Resour. Policy 37:346-357. https://doi.org/ 10.1016/j.resourpol.2012.04.002

Ruokonen E (2020) Preconditions for successful implementation of the Finnish standard for sustainable mining. Extr Ind Soc 7:611-620. https://doi.org/10.1016/j.exis.2020.03.008

Sairinen R, Tiainen H, Mononen T (2017) Talvivaara mine and water pollution: an analysis of mining conflict in Finland. Extr Ind Soc 4: 640-651

Suopajärvi L, Ejdemo T, Klyuchnikova E, Korchak E, Nygaard V, Poelzer G (2017) Social impacts of the 'glocal' mining business: case studies from Northern Europe. Miner. Econ. 30:31-39. https://doi.org/10.1007/s13563-016-0092-5

Suopajärvi L, Umander K, Leneisja J (2019) Social license to operate in the frame of social capital exploring local acceptance of mining in two rural municipalities in the European North. Resour. Policy 64: 1-7. https://doi.org/10.1016/j.resourpol.2019.101498

Tewdwr-Jones M, Allmendinger P (1998) Deconstructing communicative rationality: a critique of Habermasian collaborative planning. Environ. Plan A. 30:1975-1989

Thomson I, Boutilier R (2011) Social license to operate. In: Darling P (ed) SME mining engineering handbook. Society for Mining, Metallurgy, and Exploration, Colorado, pp 673-690.

Yrjö-Koskinen (2015). Presentation: introduction to the Finnish Network for Sustainable Mining. https://www.bgr.bund.de/EN/Themen/ Min_rohstoffe/Veranstaltungen/Rohstoffkonferenz2015/Koskinen. pdf?_blob=publicationFile \&v $=2$ [accessed 5 October 2018]

Zhang A, Moffat K, Lacey J, Wang J, Gonzalez R, Uribe K, Cui L, Dai U (2015) Understanding the social licence to operate of mining at the national scale: a comparative study of Australia, China and Chile. J.Clean.Prod 108:1063-1072. https://doi.org/10.1016/j.jclepro. 2015.07.097

Zhang A, Measham T, Moffat K (2018) Preconditions for social licence: the importance of information in initial engagement. J. Clean. Prod 172:1559-1566. https://doi.org/10.1016/J.jclepro.2017.10.323

Publisher's note Springer Nature remains neutral with regard to jurisdictional claims in published maps and institutional affiliations. 